Article

\title{
Epoxidation of Carbon Nanocapsules: Decoration of Single-Walled Carbon Nanotubes Filled with Metal Halides
}

\author{
Lucia D'Accolti ${ }^{1}$ (D), Agnieszka Gajewska ${ }^{2}$, Magdalena Kierkowicz ${ }^{3}$, Markus Martincic ${ }^{3}$, \\ Angelo Nacci ${ }^{1}$ (i) , Stefania Sandoval ${ }^{3}$, Belén Ballesteros ${ }^{4}$ (i) , Gerard Tobias ${ }^{3, *}$ (i), \\ Tatiana Da Ros $2, *$ (D) and Caterina Fusco $5, *$ (iD \\ 1 Department of Chemistry, University of Bari “A. Moro", Via Orabona, 4, 70126 Bari, Italy; \\ lucia.daccolti@uniba.it (L.D.); angelo.nacci@uniba.it (A.N.) \\ 2 INSTM Unit of Trieste, Department of Chemical and Pharmaceutical Sciences, University of Trieste, \\ Via L. Giorgieri 1, 34127 Trieste, Italy; agnikus@gmail.com \\ 3 Institut de Ciencia de Materials de Barcelona (ICMAB-CSIC), Bellaterra, 08193 Barcelona, Spain; \\ mkierkowicz@gmail.com (M.K.); markus.martincic@gmail.com (M.M.); ssandoval@icmab.es (S.S.) \\ 4 Catalan Institute of Nanoscience and Nanotechnology (ICN2), CSIC and The Barcelona Institute of Science \\ and Technology, Campus UAB, Bellaterra, 08193 Barcelona, Spain; belen.ballesteros@icn2.cat \\ 5 CNR-ICCOM, Department of Chemistry, University of Bari, Via Orabona, 4, 70126 Bari, Italy \\ * Correspondence: gerard.tobias@icmab.es (G.T.); daros@units.it (T.D.R.); fusco@ba.iccom.cnr.it (C.F.); \\ Tel.: +34-935-801-853 (G.T.); +39-040-5583-597 (T.D.R.); +39-080-5442-070 (C.F.)
}

Received: 29 January 2018; Accepted: 26 February 2018; Published: 28 February 2018

\begin{abstract}
Methyl(trifluoromethyl)dioxirane (TFDO) can be used for the oxyfunctionalization of SWCNTs filled with $\mathrm{NaI}$ and $\mathrm{LuCl}_{3}$ under mild conditions. The chosen metal halides are of interest for theranostics, both for imaging and therapy when in their radioactive form. The applied functionalization methodology does not require metal catalyst, preserves the integrity of the nanotubes during treatment, avoiding the release of the filling material. In this way, epoxidation can be considered as an efficient methodology for the functionalization of carbon nanocapsules, where the traditional harsh oxidation conditions by acids are not applicable.
\end{abstract}

Keywords: SWCNT; TFDO; epoxidation; nanocapsules filling

\section{Introduction}

Single-walled carbon nanotubes (SWCNTs) present unique physical, chemical properties and, in recent times, have emerged as a novel class of multifunctional nanomaterials, with application as sensors and biosensors, [1-5] nanoprobes [6] and as potential drug delivery vehicles for therapeutic agents in nanomedicine [3,4]. In fact, their surface area can be exploited to add different biological molecules, so as to create appropriate systems for drug delivery [3,4]. The encapsulation of compounds inside nanotubes offers a new type of sustained nanocomposites for diverse range of application [7-11]. For instance, CNTs filled with paramagnetic metal ions may be managed by an external magnetic field, which would allow the controlled delivery of drugs loaded in the CNT cavities.

One of the most important strategies to render CNTs biocompatible and dispersible in aqueous solutions is their surface modification, through which functional groups are covalently linked to the walls or to ends of the CNTs [3,4].

As tool for functionalization, the oxidation of CNTs introduces functional groups that could be allowed to react with other compounds, providing new structures. For example, in bio-related applications, CNTs are usually treated with strong acids, generating functional groups (predominantly 
carboxylic acid) on the surface and the tips of CNTs, which allows the dispersion of CNTs in aqueous solution [12]. This approach is really harsh and it is commonly used to open the tips of the tubes.

Mild oxidation methods that can generate oxygen functional groups on CNTs almost maintaining their pristine characteristics is challenging for the preparation of a versatile platform. Oxidation with strong acids can strongly alter the graphitic structure and create defects and holes in the structures [13,14]. In some applications, non-destructive methods are essential to introduce groups without heavily modifying the CNTs surface. This is for instance the case when CNTs are loaded with radiotracers. The creation of structural defects would result in leakage of the radionuclides from the interior of the CNTs and their accumulation into high affinity organs [10].

Dioxiranes (1, Figure 1) are known to be useful in the selective oxidation of a many organic compounds under mild conditions [15]. Their application for the synthesis of dimethyldioxirane (1a; DDO) [16,17] and methyl(trifluoromethyl)dioxirane (1b; TFDO) [18-20] allowed to prepare important products in organic synthesis [21-24]. TFDO (1b) is an efficient, selective, and environmentally sustainable oxygen-transfer reagent, which can be employed at low temperatures (as at least $0{ }^{\circ} \mathrm{C}$ ) in the epoxidation of $\mathrm{C}=\mathrm{C}$ double bonds. Its use is a valuable option to avoid peracids in epoxidation, thanks to improved reaction rates and capability to give epoxidation under neutral conditions [15,21-24].

We have shown that the oxidation of SWCNTs [25] and MWCNTs [26] into their epoxy group derivative under mild conditions can be obtained using isolated TFDO (1b, Figure 1).

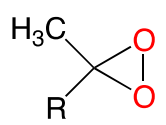

1

1a: $\mathrm{R}=\mathrm{CH}_{3}$

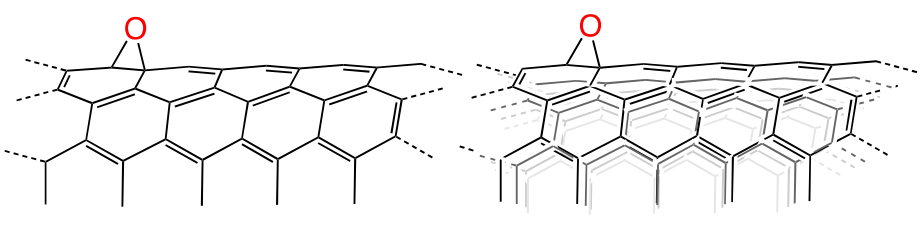

ox-SWCNTS

ox-MWCNTs

1b: $\mathrm{R}=\mathrm{CF}_{3}$

Figure 1. Chemical structure of 1, $o x$-SWCNTs and $o x$-MWCNTs.

Considering these achievements, it appeared convenient to explore the surface modification of SWCNTs filled with non-radioactive metal halides $\left(\mathrm{NaI}\right.$ and $\left.\mathrm{LuCl}_{3}\right)$, with the aim of proving that the whole process is properly applicable also to close-ended filled SWCNTs (referred to as "carbon nanocapsules" [11]) without causing leakage of the encapsulated compounds. If so, the developed approach could then be employed with nanocapsules loaded with the respective radionuclides (for instance $\mathrm{Na}^{125} \mathrm{I}$ and ${ }^{177} \mathrm{LuCl}_{3}$ ) of interest for biomedical imaging and therapy, thus increasing the orthogonality of the functionalization process and opening new scenarios in their derivatization.

This study is the natural progression of the previous works $[25,26]$ in which the efficacy of the functionalization on empty single walled and multiwalled nanotubes by means of dioxirane epoxidation has been demonstrated. Herein, we report the surface decoration of biomedically relevant metal halide-filled SWCNTs using the powerful dioxirane $\mathbf{1 b}$. This method preserves the integrity of the nanotube structure and allows for their successive derivatization (epoxide opening) by means of a diamine $[25,26]$.

The decorated SWCNTs were characterized by Fourier transform infrared (FT-IR), thermogravimetric (TGA), Raman analysis, and transmission electron microscopy (TEM).

\section{Materials and Methods}

The procedure of methyl(trifluoromethyl)dioxirane preparation (1) has been already reported [21]. TGA of pristine and functionalized CNTs were performed on Q500 (TA Instruments) under $\mathrm{N}_{2}$ atmosphere by equilibrating at $100{ }^{\circ} \mathrm{C}$, and following a ramp of $10^{\circ} \mathrm{C} \mathrm{min}-1$ up to $800{ }^{\circ} \mathrm{C}$ with a flow rate of $90 \mathrm{~mL} \mathrm{~min}^{-1}$. Less than $1 \mathrm{mg}$ of compound per each analysis was required. Reported 
plots are an average of at least two measurements. The degree of functionalization as $\mu \mathrm{mol} / \mathrm{g}$ was calculated using the following formula:

$$
\frac{\mu \mathrm{mol}}{\mathrm{g}}=\frac{\text { weight loss }(\%) \cdot 10000}{\text { Molecular weight of functional group }}
$$

Raman spectra were recorded with a Renishaw inVia Raman microscope (50 objective) using $633 \mathrm{~nm} \mathrm{He} / \mathrm{Ne}$ laser $(17 \mathrm{~mW})$ at room temperature with a low laser power.

Infrared analyses were carried out in the $400-4000 \mathrm{~cm}^{-1}$ range (4 on 32 scans) with Fouriertransform infrared (FTIR) spectrometers (PerkinElmer Spectrum BX and System2000).

HAADF-STEM and HRTEM images were acquired using an FEI Tecnai G2 F20 microscope operated at $200 \mathrm{kV}$.

Common commercial solvents and reagents of high purity were employed. Commercial triple salt $2 \mathrm{KHSO}_{5} \cdot \mathrm{KHSO}_{4} \cdot \mathrm{K}_{2} \mathrm{SO}_{4}$ (trade name, Caroat ${ }^{\circledR}$ ), a gift from Peroxid-Chemie (Degussa, Germany) was our source of potassium monoperoxysulfate for the synthesis of TFDO, $\mathbf{1 b}$. Chemical vapour deposition SWCNTs (Elicarb ${ }^{\circledR}$ ) were provided by Thomas Swan \& Co. Ltd. (Consett, UK) with an average diameter of $2.1 \mathrm{~nm}$ (value provided by the supplier). $\mathrm{LuCl}_{3} @ S W N C T$ s were prepared following the protocol previously described [27]. Briefly, pristine SWCNTs were steam treated at $900{ }^{\circ} \mathrm{C}$ for $4 \mathrm{~h}$ followed by an $\mathrm{HCl}$ wash [28], which leads to a median length of $420 \mathrm{~nm}$. The so obtained SWCNTs were filled with $\mathrm{LuCl}_{3}$ by molten phase capillary filling, by annealing a mixture of SWCNTs and $\mathrm{LuCl}_{3}$ at $950{ }^{\circ} \mathrm{C}$ for $12 \mathrm{~h}$ under vacuum. The resulting sample consists on closed-ended [29] and filled SWCNTs containing a large excess of non-encapsulated $\mathrm{LuCl}_{3}$, which was removed from the sample of using a Soxhlet with dialysis sack system [27]. Similarly, NaI was encapsulated by molten phase capillary filling, by annealing a mixture of steam purified SWCNTs and NaI (1:10 wt. ratio) at $900{ }^{\circ} \mathrm{C}$ in a silica ampoule under vacuum. The external $\mathrm{NaI}$ was removed by washing the collected sample with water, under reflux during $24 \mathrm{~h}$. The powder was collected by filtration on top of a polycarbonate membrane $(0.2 \mu \mathrm{m}$ pore $)$ and subsequently dried overnight at $60^{\circ} \mathrm{C}$.

Preparation of ox-NaI@SWCNTs (3a). An aliquot of the standardized cold solution of dioxirane $\mathbf{1 b}$ $(0.6 \mathrm{M}, 2.5 \mathrm{~mL}, 1.2 \mathrm{mmol})$ in 1,1,1-trifluoropropanone (TFP) was added to a suspension of pristine NaI@SWCNTs 2a $(16.34 \mathrm{mg})$ in cold $\left(0{ }^{\circ} \mathrm{C}\right) \mathrm{CH}_{2} \mathrm{Cl}_{2}(20 \mathrm{~mL})$, previously sonicated for $30 \mathrm{~min}$. The reaction was stirred at room temperature for $12 \mathrm{~h}$. The final product was washed many times with $\mathrm{CH}_{2} \mathrm{Cl}_{2}$ followed by $\mathrm{MeOH}$ and dried in vacuum to afford $19.7 \mathrm{mg}$ of oxidized product 3a. FT-IR (spectrum in KBr pellets): $v$ 3340, 1715, 1552, $1086 \mathrm{~cm}^{-1}$.

Preparation of ox- $\mathrm{LuCl}_{3} @ S W C N T s(3 \mathbf{b})$. The analogue procedure was used with a suspension of pristine $\mathrm{LuCl}_{3} @ S W C N T s \mathbf{2 b}(17.87 \mathrm{mg})$ in $\mathrm{CH}_{2} \mathrm{Cl}_{2}(20 \mathrm{~mL})$, previously sonicated for $30 \mathrm{~min}$, obtaining $\mathbf{3 b}$ (22.3 mg). FT-IR (spectrum in KBr pellets): $v 3340,1725,1550,1083 \mathrm{~cm}^{-1}$.

Functionalization of ox-MX@SWCNT (3) with 1,6-Hexa-Methylendiamine. Nanotubes ox-NaI@SWCNTs 3a $(17.8 \mathrm{mg}$ ) were dispersed in 1,6-hexamethylenediamine $(3.1 \mathrm{~g})$ and the mixture was heated to reflux at $140{ }^{\circ} \mathrm{C}$ for $12 \mathrm{~h}$ under $\mathrm{N}_{2}$. Then the mixture was diluted with $\mathrm{MeOH}(20 \mathrm{~mL})$ and filtered by using a $0.2 \mu \mathrm{m}$ PTFE membrane filter and the solid was washed many times with $\mathrm{CH}_{2} \mathrm{Cl}_{2}$ and $\mathrm{MeOH}$ to remove unreacted 1,6-hexamethylenediamine. The resulting material was dried under vacuum to give 4a (23 mg). FT-IR (spectrum in KBr pellets): $v$ 3367, 2914, 2845, 1552, 1450, 1381, 1235, 1214, $1090 \mathrm{~cm}^{-1}$. The same procedure was applied for the functionalization of $\mathbf{3 b}$ with 1,6-hexamethylenediamine. The degree of functionalization was obtained by TGA, comparing the value of weight loss of $4 \mathbf{a}$ and $\mathbf{4} \mathbf{b}$ with the ones of pristine filled SWCNTs ( $2 \mathbf{a}$ and $\mathbf{2 b}$ ) and it results 9.7\% for $f$-NaI@SWCNT (4a) and 11.9\% for $f-\mathrm{LuCl}_{3} @ S W C N T$ (4b). FT-IR (spectrum in KBr pellets): v 3271, 2917, 2850, 1560, 1449, 1379, $1235,1214,1089 \mathrm{~cm}^{-1}$. 


\section{Results and Discussion}

The covalent functionalization of SWCNTs filled with $\mathrm{NaI}$ (NaI@SWCNTs) or $\mathrm{LuCl}_{3}$ (LuCl $3 @ S W C N T s)(\mathbf{2 a}-\mathbf{b}$, Figure 2) was performed with dioxirane $\mathbf{1 b}$. The metal halide nanocapsules, MX@SWCNTs (where MX indicates either $\mathrm{NaI}$ or $\mathrm{LuCl}_{3}$ ), were prepared by molten phase filling at high temperature, following the protocols detailed in the experimental section, thus leading to samples of closed-ended filled SWCNTs [29].

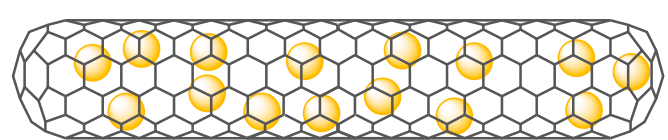

MX@SWCNT (2) 2a: Nal@SWCNT 2b: LuCl 3 @SWCNT

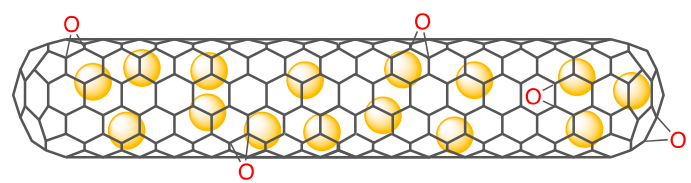

ox-MX@SWCNT (3)

3a: ox-Nal@SWCNT

3b: ox- $\mathrm{LuCl}_{3} @$ SWCNT

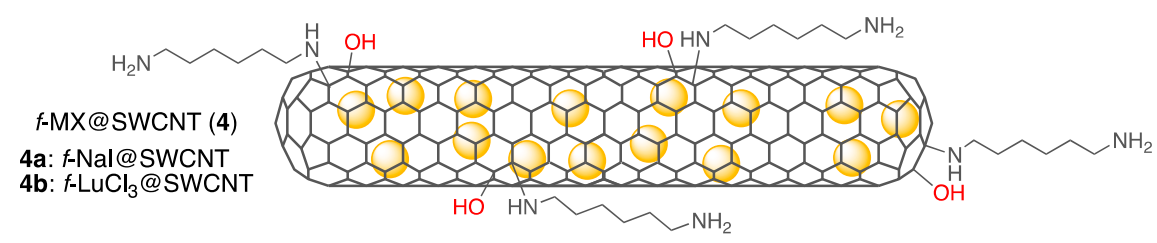

Figure 2. Schematic representation of MX@SWCNTs 2, ox-MX@SWCNTs 3 and $f$-MX@SWCNTs 4.

\subsection{Oxidation of MX@SWCNT with Isolated TFDO (1b)}

The as-prepared MX@SWCNTs were treated with 1b mainly obtaining the introduction of epoxide groups onto the SWCNTs sidewalls. A stock solution $(0.5-0.6 \mathrm{M})$ of $\mathbf{1 b}$ can be prepared by the procedure previously described [21] from 1,1,1-trifluoropropanone (TFP) and stored at $-20{ }^{\circ} \mathrm{C}$ for months.

In a typical reaction, $16 \mathrm{mg}$ of MX@SWCNTs (2a or $\mathbf{2 b}$ ) were dispersed in $\mathrm{CH}_{2} \mathrm{Cl}_{2}$ (dry, $20 \mathrm{~mL}$ ) by sonication for $30 \mathrm{~min}$. To this suspension, dioxirane $(\mathbf{1 b})$ was added and the mixture was stirred at $25^{\circ} \mathrm{C}$ for 12 hours. Scheme 1 shows the decoration of the external surface of $\mathbf{2}$ by means of $\mathbf{1 b}$ [25].
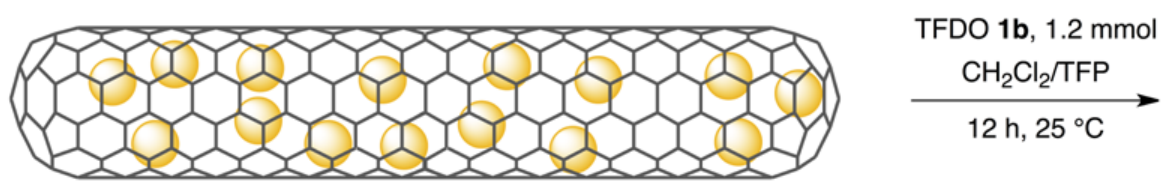

MX@SWCNT (2)

2a: Nal@SWCNT

2b: $\mathrm{LuCl}_{3} @ S W C N T$

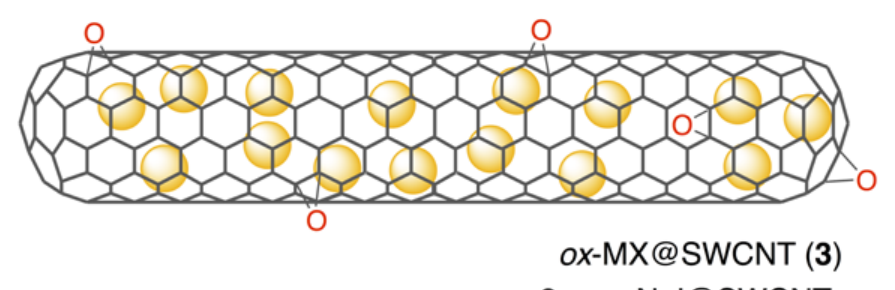

3a: ox-Nal@SWCNT

3b: ox-LuCl 3 @SWCNT

Scheme 1. MX@SWCNTs epoxidation with TFDO (1b).

Subsequently, ox-MX@SWCNTs 3 were recovered by filtration on a $0.2 \mu \mathrm{m}$ PTFE membrane filter and systematically treated several times with $\mathrm{CH}_{2} \mathrm{Cl}_{2}$ and $\mathrm{MeOH}$ by filtration/washing workup procedure. Then, the oxidized nanotubes 3 were dried under vacuum. 


\subsection{Post-Functionalization of ox-MX@SWCNTs 3 with 1,6-Hexamethylenediamine}

Epoxide functional groups provide a large versatility for further subsequent derivatization. Due to their ability to undergo nucleophilic attack with subsequent ring opening, this is a starting point for a wide range of CNTs modifications. As a matter of fact, this process is designed to chemically attack the CNTs sidewall, allowing further covalent derivatization, as already reported and demonstrated by model reaction $[25,26,30]$.

The generation of hydroxyl and amine functional groups on the CNTs allows the preparation of highly functionalized samples.

The reaction between $o x$-MX@SWCNTs 3 and an aliphatic diamine (1,6-hexamethylendiamine) was performed. This reagent was chosen to introduce multimodality to the obtained constructs (Scheme 2).

To obtain this, $\mathbf{3 a}$ is dispersed in excess of 1,6-hexa-methylenediamine to exclude the formation of cross-linking among the tubes and heated at reflux for $12 \mathrm{~h}$ under inert atmosphere $\left(\mathrm{N}_{2}\right)$. Afterwards, the resulting suspension is subjected to sonication/washing cycles and then filtered on a $0.2 \mu \mathrm{m}$ PTFE membrane.

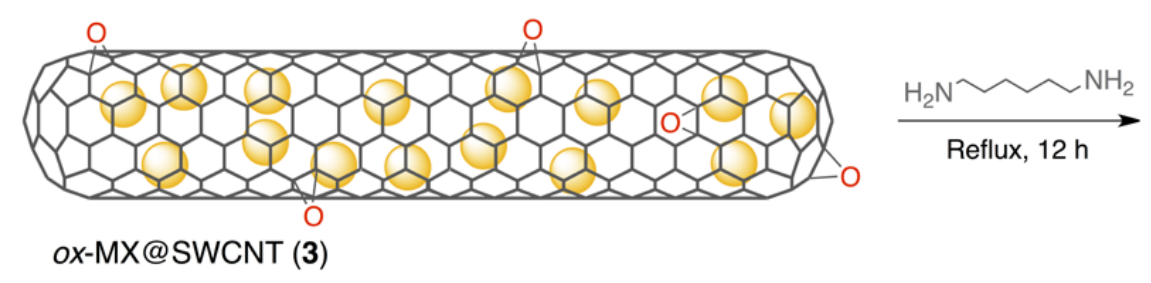

3a: ox-Nal@SWCNT

3b: ox $-\mathrm{LuCl}_{3} @ S W C N T$

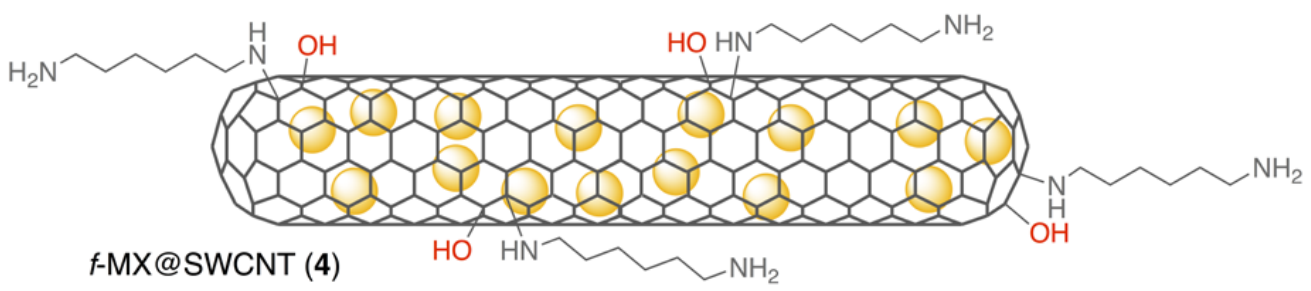

4a: f-Nal@SWCNT

4b: $f-\mathrm{LuCl}_{3} @ S W C N T$

Scheme 2. Functionalization of $o x-M X @ S W C N T 3$ with 1,6-hexa-methylendiamine.

IR analysis of 4 resulted useful to check the functionalization and the epoxide opening (Figure 3). An NH stretch band is present at $3271 \mathrm{~cm}^{-1}$, together with a band at $3367 \mathrm{~cm}^{-1}$ related to the $\mathrm{NH}_{2}$ symmetric stretch. Moreover, signals at 1450 and $1381 \mathrm{~cm}^{-1}$, attributable to the bending band of the $\mathrm{CH}_{2}$ group, were detected, and signals at 1235 and $1214 \mathrm{~cm}^{-1}$, attributed to $\mathrm{C}-\mathrm{N}$ bending, were also found [25]. 


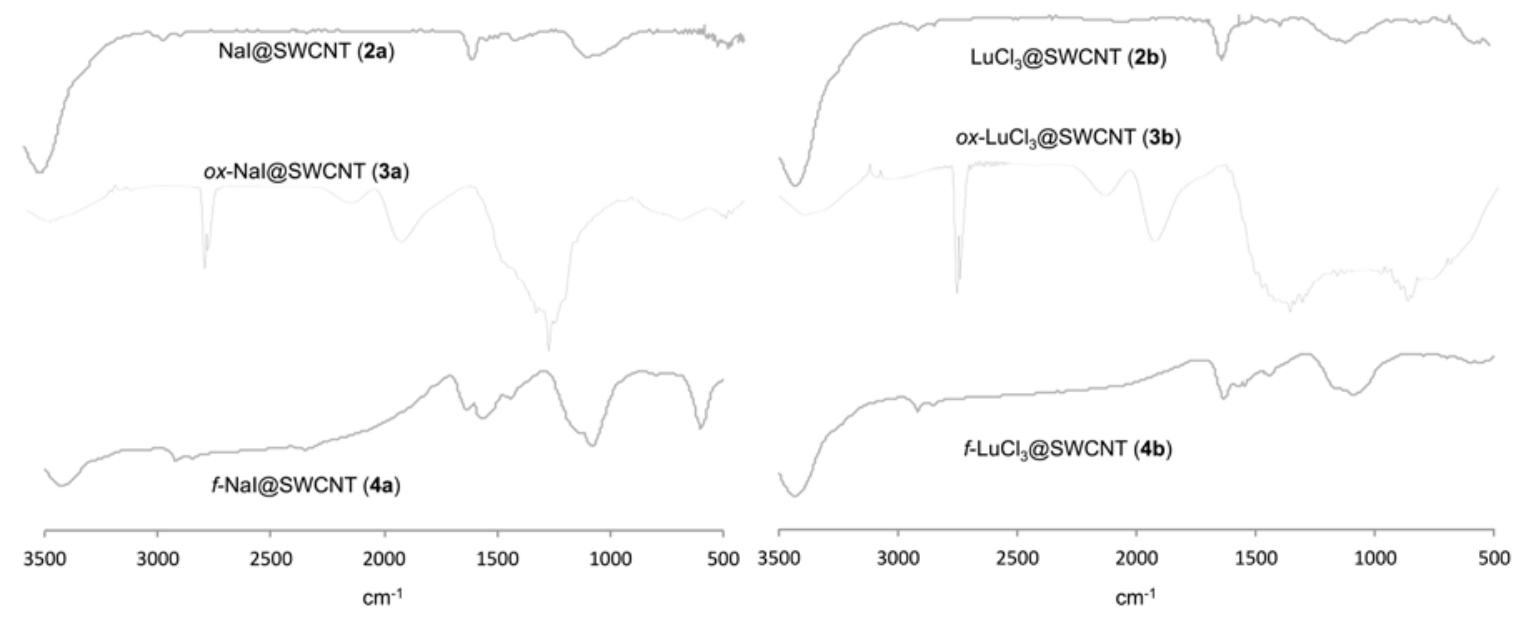

Figure 3. FT-IR spectra of MX@SWCNT 2,ox-MX@SWCNT 3, (light grey) and f-MX@SWCNT 4.

The presence of covalently linked organic moieties on $f$-MX@SWCNTs walls was investigated by thermogravimetric analysis, under nitrogen atmosphere in the temperature range from 100 to $800^{\circ} \mathrm{C}$. The TGA curves of MX@SWCNTs and f-MX@SWCNTs, i.e., before the chemical treatment and after epoxidation/amination, are depicted in Figure 4. Samples after modification ( $f$-MX@SWCNTs) showed a weight loss starting at temperatures above $150{ }^{\circ} \mathrm{C}$ with respect to not modified MX@SWCNTs. At $500{ }^{\circ} \mathrm{C}$ the mass loss, attributable to the degradation of covalently attached organic moieties, was of $11.9 \%$ for the $f-\mathrm{LuCl}_{3} @ S W C N T s$ and $9.7 \%$ for $f$-NaI@SWCNTs corresponding to a calculated degree of functionalization (f) of $900 \mu \mathrm{mol} / \mathrm{g}$ and $730 \mu \mathrm{mol} / \mathrm{g}$, respectively.

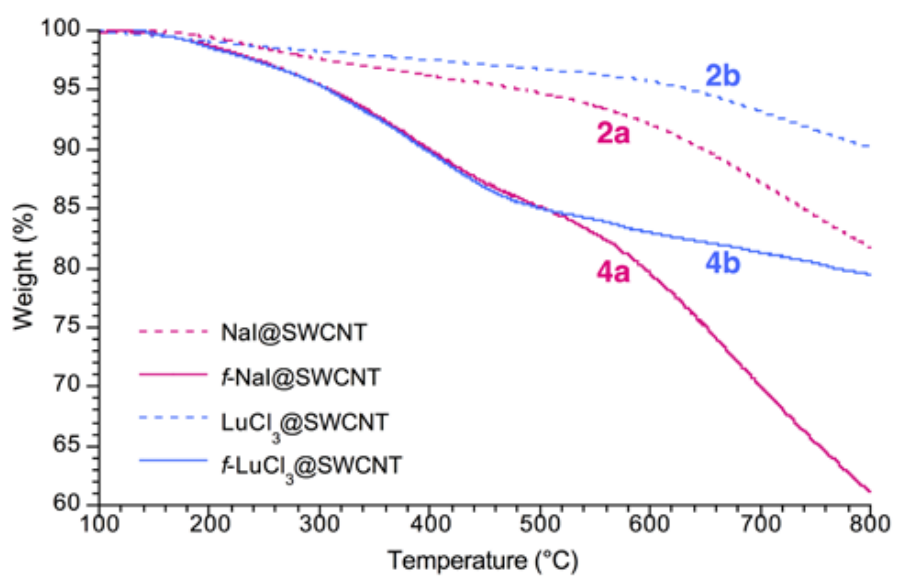

Figure 4. TGA curves of 2 (MX@SWCNTs) and 4 ( $f$-MX@SWCNTs) under flowing nitrogen.

Raman spectroscopy represents an effective technique to characterize SWCNTs. The typical Raman spectrum shows a split tangential G mode located at $\sim 1580 \mathrm{~cm}^{-1}$. This band represents the $\mathrm{sp}^{2}$ in-plane bond-stretching of $\mathrm{C}$ atoms in graphite-like structures. The D mode at $\sim 1350 \mathrm{~cm}^{-1}$ becomes evident if $\mathrm{sp}^{3} \mathrm{C}$ atoms are introduced in the $\mathrm{sp}^{2}$ carbon lattice [31]. The radial breathing mode (RBM) between 130 and $300 \mathrm{~cm}^{-1}$ corresponds to the coherent vibration of the $\mathrm{C}$ atoms in the radial direction of the nanotube and it is shown in the $100-350 \mathrm{~cm}^{-1}$ window in Figure 5, panel A. For the functionalized samples (solid lines) we found a general decrease in the RBM intensities of the lower frequency side. We interpreted this behavior as an indication of changes in the electronic structure of the tubes. 
From the intensity ratio of the Raman $\mathrm{D}$ and $\mathrm{G}$ modes (AD/AG ratio) [32] it is possible to estimate the defect concentration in SWCNTs. The AD/AG ratios were corrected by the $\mathrm{AD}_{0} / \mathrm{AG}_{0}$ values of not modified MX@SWCNT material. The D and G bands of compounds 2 and 4 are shown together (Figure 5, panel B).
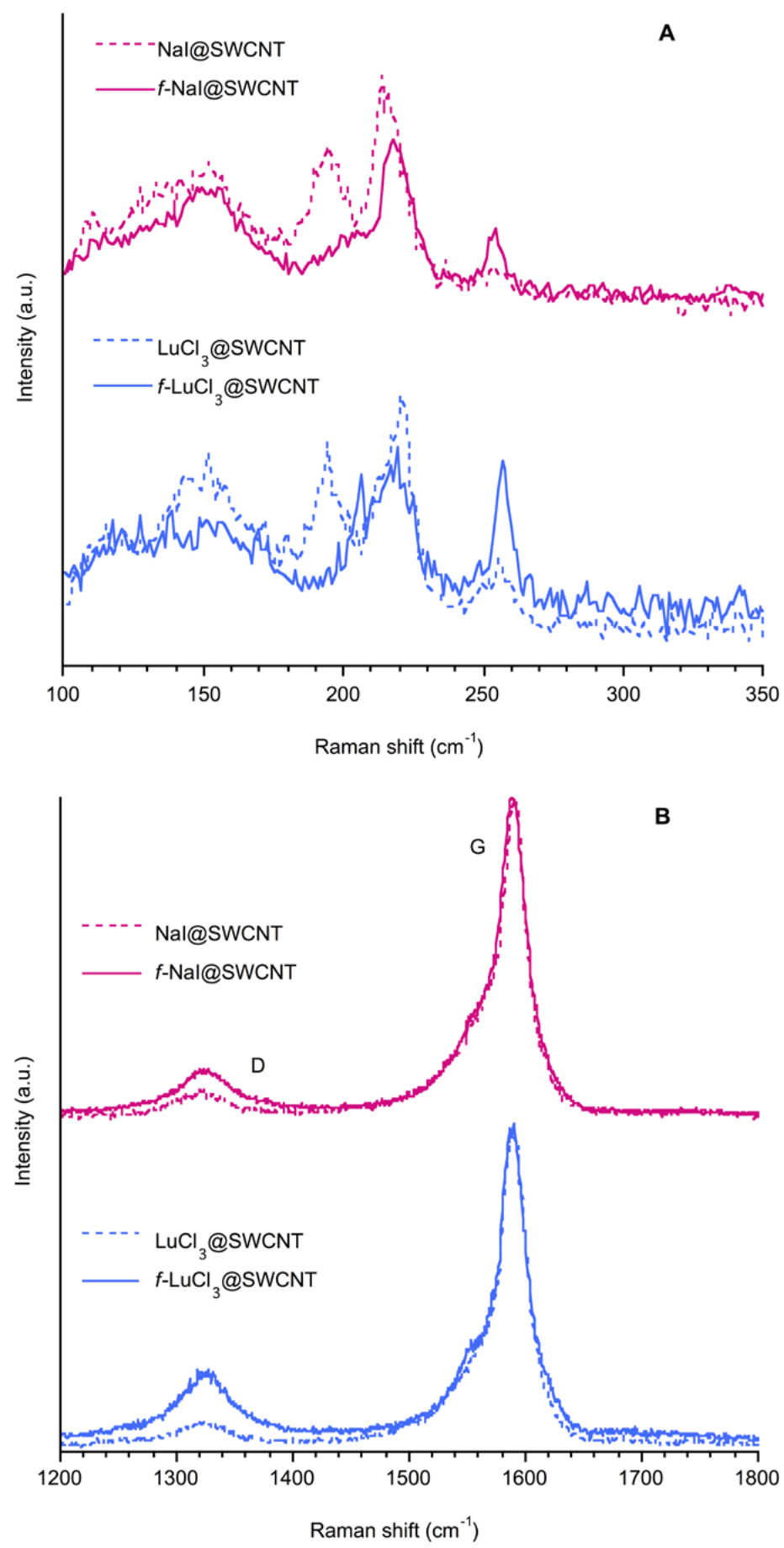

Figure 5. Raman spectra of 2 (dashed lines) and 4 (solid lines) with a $633 \mathrm{~nm}$ laser. Panel A: RBMs mode; Panel B: D mode and G mode. Spectra are normalized for ease of comparison.

The $\mathrm{D}$ mode increased with the increased defects concentration and it is much higher after functionalization with amine in comparison to starting material MX@SWCNTs. The (AD/AG)/(AD $\left.\mathrm{A}_{0} / \mathrm{AG}_{0}\right)$ 
ratios are compared to the functionalization degrees calculated from the weight loss of the TGA and are shown in Table 1.

Table 1. Screening of different SWCNTs filled with biomedical relevant payloads and modified by oxidation and amination.

\begin{tabular}{|c|c|c|c|}
\hline Products & Weight Loss ${ }^{1}(\%)$ & $\mathrm{f}^{2}(\mu \mathrm{mol} / \mathrm{g})$ & $(\mathrm{AD} / \mathrm{AG}) /\left(\mathrm{AD}_{0} / \mathrm{AG}_{0}\right)^{3}$ \\
\hline f-NaI@SWCNTs (4a) & 9.7 & 730 & 1.8 \\
\hline$f-\mathrm{LuCl}_{3} @ S W C N T s(4 \mathbf{b})$ & 11.9 & 900 & 2.1 \\
\hline
\end{tabular}

1 Weight loss obtained at $500{ }^{\circ} \mathrm{C} .{ }^{2}$ Degree of functionalization $\mathrm{f}(\mu \mathrm{mol} / \mathrm{g})$ calculated from the measured weight loss. $3(\mathrm{AD} / \mathrm{AG}) /\left(\mathrm{AD}_{0} / \mathrm{AG}_{0}\right)$ ratios obtained from Raman spectroscopy at $633 \mathrm{~nm}$.
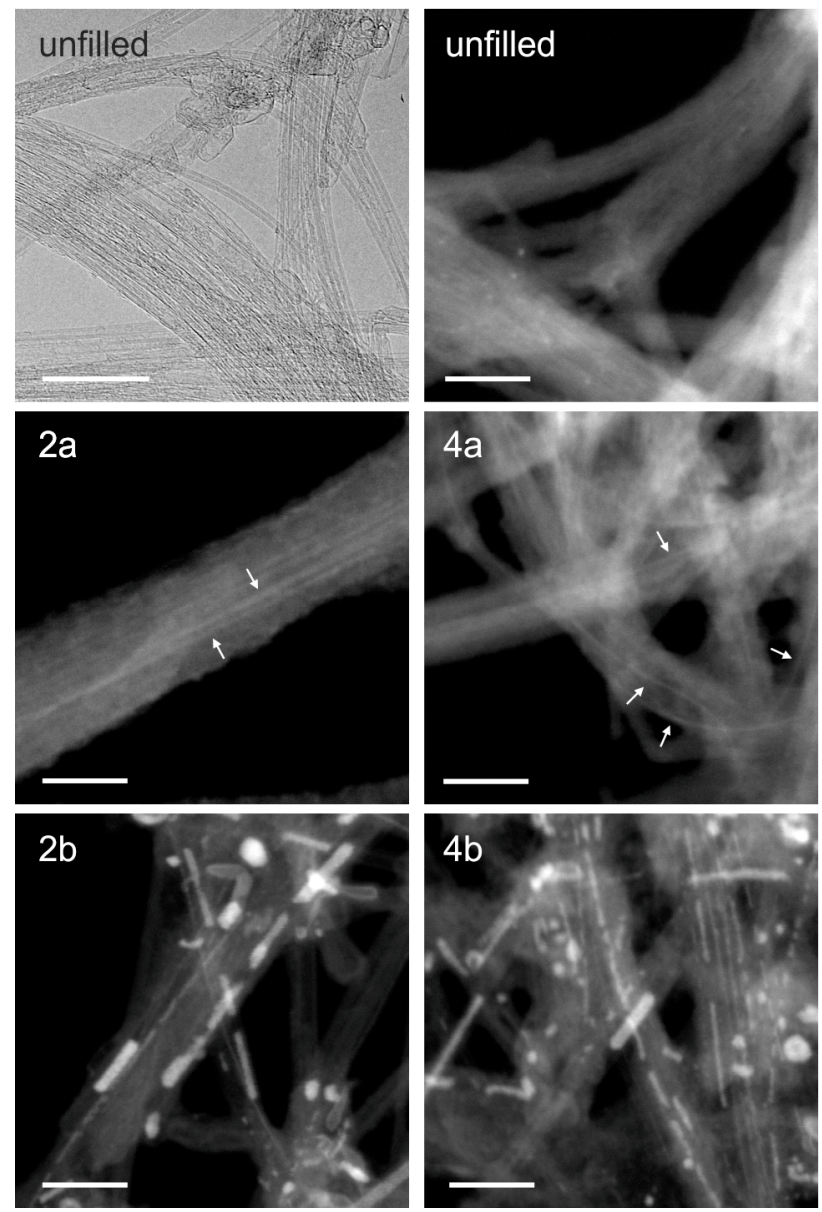

Figure 6. HRTEM and HAADF-STEM images of unfilled SWCNTs (first row); HAADF-STEM images of $2 \mathbf{a}, \mathbf{4 a}, \mathbf{2 b}$ and $\mathbf{4 b}$. Scale bar: $20 \mathrm{~nm}$.

HAADF-STEM images taken on the filled SWCNTs $\mathbf{2} \mathbf{a}$ and $\mathbf{2} \mathbf{b}$ show the presence of the encapsulated metal halides inside the tubes, as visible from Figure 6. In this imaging mode, the intensity is approximately proportional to the square of the atomic number; therefore the bright lines that follow the shape of the CNTs correspond to the filling material. This contrast is not observed in the HAADF-STEM image of the unfilled tubes (Figure 6, first row). Remarkably, when comparing the filled tubes $\mathbf{2} a$ and $\mathbf{2 b}$ with their functionalized counterparts $\mathbf{4 a}$ and $\mathbf{4 b}$, the same degree of filling is observed. Therefore it can be concluded that the filling is preserved upon functionalization.

Even though the purpose of this work was to demonstrate the applicability of this procedure to gently oxidize the tubes while preserving their content, the use of such strategy allowed also to obtain materials with better water-dispersibility. In a qualitative experiment $1 \mathrm{mg}$ of $\mathbf{2 a}$ and of $4 \mathbf{a}$ were 
dispersed in $1 \mathrm{~mL}$ of distilled water and sonicated for $2 \mathrm{~min}$. As appreciable from Figure 7 a better suspension was obtained for $\mathbf{4 a}$, but in both cases the compounds settled to the bottom in for $10 \mathrm{~min}$.

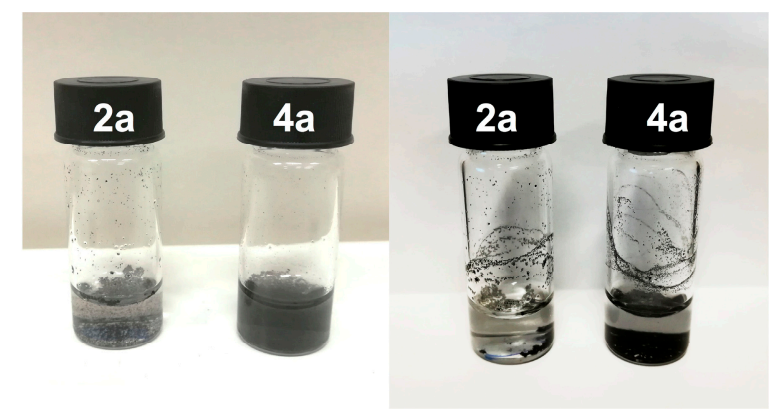

Figure 7. Suspensions of $\mathbf{2 a}$ and $\mathbf{4 a}$ in $\mathrm{H}_{2} \mathrm{O}\left(1 \mathrm{mg} \cdot \mathrm{mL}^{-1}\right)$ just after sonication (left panel) and $10 \mathrm{~min}$ later (right panel).

\section{Conclusions}

In summary, we report on the decoration of closed-ended filled carbon nanotubes (carbon nanocapsules) with epoxide groups under mild conditions by TFDO. This reaction does not necessitate of metal catalyst and maintained the CNT structure, in particular the closed ends of the nanotubes during treatment. Remarkably, in this procedure there is no need of an oxidizing acid treatment that would damage the structure of the nanotubes, especially on the tips, during the oxidation process. In this way the tips stay sealed while for instance nitric acid treatment of filled SWCNTs results in the complete leakage of the encapsulated metal halides because the ends are re-opened.

The subsequent transformation of the epoxides introduced on the $o x$-MX@SWCNT is obtained with the epoxide ring-opening by means of a primary diamine. Such an approach highlights the versatility of the $o x$-MX@SWCNT as valuable platforms for their successive functionalization/ derivatization with selected reactive nucleophiles in addition to providing multimodality to the final derivatives.

Acknowledgments: The research leading to these results has received funding from the PEOPLE Programme (Marie Curie Actions) of the European Union's Seventh Framework Programme FP7/2007-2013/under REA grant agreement no. 290023 (RADDEL); and Regione Puglia MIUR PON Ricerca e Competitività 20072013 Avviso 254/Ric. del 18/05/2011, Project PONa3 00369, Laboratorio SISTEMA, and from University of Trieste (FRA 2015). ICMAB and ICN2 acknowledge financial support from the Spanish Ministry of Economy and Competitiveness, through the "Severo Ochoa" Programme for Centres of Excellence in R\&D (SEV-2015-0496 and SEV-2013-0295). ICN2 is funded by the CERCA programme. The authors are grateful to Thomas Swan \& Co. Ltd. for providing Elicarb ${ }^{\circledR}$ carbon nanotubes. The authors wish to thank Annarita Armenise for skillful assistance.

Author Contributions: L.D., C.F. and A.N. conceived and designed the experiments; A.G. performed the experiments; T.D.R. and A.G. analyzed the data; M.K., M.M., S.S. and G.T. prepared and characterized not-functionalized filled CNTs; B.B. contributed with HRTEM and HAADF-STEM analyses; C.F., T.D.R. and G.T. wrote the paper.

Conflicts of Interest: The authors declare no conflict of interest.

\section{References}

1. Baughman, R.H.; Zakhidov, A.A.; de Heer, W.A. Carbon nanotubes-The route toward applications. Science 2002, 297, 787-792. [CrossRef] [PubMed]

2. Ehli, C.; Oelsner, C.; Guldi, D.M.; Mateo-Alonso, A.; Prato, M.; Schmidt, C.; Backes, C.; Hauke, F.; Hirsch, A. Manipulating single-wall carbon nanotubes by chemical doping and charge transfer with perylene dyes. Nat. Chem. 2009, 1, 243-249. [CrossRef] [PubMed]

3. Tasis, D.; Tagmatarchis, N.; Bianco, A.; Prato, M. Chemistry of carbon nanotubes. Chem. Rev. 2006, 106, 1105-1136. [CrossRef] [PubMed] 
4. Prato, M.; Kostarelos, K.; Bianco, A. Functionalized Carbon Nanotubes in Drug Design and Discovery. Acc. Chem. Res. 2008, 41, 60-68. [CrossRef] [PubMed]

5. Davis, J.J.; Coleman, K.S.; Azamian, B.R.; Bagshaw, C.B.; Green, M.L.H. Chemical and Biochemical Sensing with Modified Single Walled Carbon Nanotubes. Chem. Eur. J. 2003, 9, 3732-3739. [CrossRef] [PubMed]

6. Dai, H.; Hafner, J.H.; Rinzler, A.G.; Colbert, D.T.; Smalley, R.E. Nanotubes as nanoprobes in scanning probe microscopy. Nature 1996, 384, 147-150. [CrossRef]

7. Kostarelos, K.; Bianco, A.; Prato, M. Promises, facts and challenges for carbon nanotubes in imaging and therapeutics. Nat. Nanotechnol. 2009, 4, 627-633. [CrossRef] [PubMed]

8. Bhirde, A.A.; Patel, V.; Gavard, J.; Zhang, G.; Sousa, A.A.; Masedunskas, A.; Leapman, R.D.; Weigert, R.; Gutkind, R.J.S.; Rusling, J.F. Targeted Killing of Cancer Cells in Vivo and in Vitro with EGF-Directed Carbon Nanotube-Based Drug Delivery. ACS Nano 2009, 3, 307-316. [CrossRef] [PubMed]

9. Liu, Z.; Chen, K.; Davis, C.; Sherlock, S.; Cao, Q.; Chen, X.; Dai, H. Drug delivery with carbon nanotubes for in vivo cancer treatment. Cancer Res. 2008, 68, 6652-6660. [CrossRef] [PubMed]

10. Hong, S.Y.; Tobias, G.; Al-Jamal, K.T.; Ballesteros, B.; Ali-Boucetta, H.; Lozano-Perez, S.; Nellist, P.D.; Sim, R.B.; Finucane, C.; Mather, S.J.; et al. Filled and glycosylated carbon nanotubes for in vivo radioemitter localization and imaging. Nat. Mater. 2010, 9, 485-490. [CrossRef] [PubMed]

11. Martincic, M.; Tobias, G. Filled carbon nanotubes in biomedical imaging and drug delivery. Expert Opin. Drug Deliv. 2015, 12, 563-581. [CrossRef] [PubMed]

12. Karousis, N.; Tagmatarchis, N.; Tasis, D. Current Progress on the Chemical Modification of Carbon Nanotubes. Chem. Rev. 2010, 110, 5366-5397. [CrossRef] [PubMed]

13. Liu, J.; Rinzler, A.G.; Dai, H.; Hafner, J.H.; Bradley, R.K.; Boul, P.J.; Lu, A.; Iverson, T.; Shelimov, K.; Huffman, C.B.; et al. Fullerene pipes. Science 1998, 280, 1253-1256. [CrossRef] [PubMed]

14. Zhang, J.; Zou, H.; Qing, Q.; Yang, Y.; Li, Q.; Liu, Z.; Guo, X.; Du, Z. Effect of Chemical Oxidation on the Structure of Single-Walled Carbon Nanotubes. J. Phys. Chem. B 2003, 107, 3712-3718. [CrossRef]

15. Curci, R.; D'Accolti, L.; Fusco, C. A Novel Approach to the Efficient Oxygenation of Hydrocarbons under Mild Conditions. Superior Oxo Transfer Selectivity Using Dioxiranes. Acc. Chem. Res. 2006, 39, 1-9. [CrossRef] [PubMed]

16. Cassidei, L.; Fiorentino, M.; Mello, R.; Sciacovelli, O.; Curci, R. Oxygen-17 and carbon-13 identification of the dimethyldioxirane intermediate arising in the reaction of potassium caroate with acetone. J. Org. Chem. 1987, 52, 699-700. [CrossRef]

17. Murray, R.W.; Singh, M. Synthesis of Epoxides Using Dimethyldioxirane: Trans-Stilbene Oxide. Org. Synth. 1997, 74, 91-97. [CrossRef]

18. Mello, R.; Fiorentino, M.; Fusco, C.; Curci, R. Oxidations by Methyl(trifluoromethy1)dioxirane. 2. Oxyfunctionalization of Saturated Hydrocarbonst. J. Am. Chem. Soc. 1989, 111, 6749-6757. [CrossRef]

19. Annese, C.; D'Accolti, L.; Filardi, R.; Tommasi, I.; Fusco, C. Oxidative cleavage of lactams in water using dioxiranes: An expedient and environmentally-safe route to $\omega$-nitro acids. Tetrahedron. Lett. 2013, 54, 515-517. [CrossRef]

20. Annese, C.; Abbrescia, D.I.; Catucci, L.; D’Accolti, L.; Denora, N.; Fanizza, I.; Fusco, C.; La Piana, G. Site-dependent biological activity of valinomycin analogs bearing derivatizable hydroxyl sites. J. Pept. Sci. 2013, 19, 751-757. [CrossRef] [PubMed]

21. D'Accolti, L.; Fusco, C.; Rella, M.R.; Curci, R. Concerning synthesis of ring-A fluorinated anthracyclines. The dioxirane shunt. Synt. Commun. 2003, 33, 3009-3016. [CrossRef]

22. D'Accolti, L.; Annese, C.; Fusco, C. Dioxirane-mediated metal-free oxidations of target molecules containing unsaturated carbons. Curr. Org. Chem. 2015, 19, 45-61. [CrossRef]

23. D'Accolti, L.; Annese, C.; De Riccardis, A.; De Giglio, E.; Cafagna, D.; Fanelli, F.; Fusco, C. Dioxirane-Mediated Heterogeneous Epoxidations with Potassium Caroate: A Solid Catalyst Bearing Anchored Ketone Moieties. Eur. J. Org. Chem. 2012, 24, 4616-4621. [CrossRef]

24. Annese, C.; D'Accolti, L.; Fusco, C.; Curci, R. Selective Hydroxylation of Methane by Dioxiranes under Mild Conditions. Org. Lett. 2011, 13, 2142-2144. [CrossRef] [PubMed]

25. Annese, C.; D'Accolti, L.; Giambastiani, G.; Mangone, A.; Milella, A.; Tuci, G.; Fusco, C. Tunable epoxidation of single-walled carbon nanotubes by isolated methyl(trifluoromethyl)dioxirane. Eur. J. Org. Chem. 2014, 8, 1666-1671. [CrossRef] 
26. Annese, C.; D’Accolti, L.; Armuzza, V.; Da Ros, T.; Fusco, C. Epoxidation of multi-walled carbon nanotubes by organocatalytic oxidation. Eur. J. Org. Chem. 2015, 2015, 3063-3068. [CrossRef]

27. Kierkowicz, M.; González-Domínguez, J.M.; Pach, E.; Sandoval, S.; Ballesteros, B.; Da Ros, T.; Tobias, G. Filling Single-Walled Carbon Nanotubes with Lutetium Chloride: A Sustainable Production of Nanocapsules Free of Nonencapsulated Material. ACS Sustain. Chem. Eng. 2017, 5, 2501-2508. [CrossRef]

28. Ballesteros, B.; Tobias, G.; Shao, L.; Pellicer, E.; Nogués, J.; Mendoza, E.; Green, M.L.H. Steam Purification for the Removal of Graphitic Shells Coating Catalytic Particles and the Shortening of Single-Walled Carbon Nanotubes. Small 2008, 4, 1501-1506. [CrossRef] [PubMed]

29. Shao, L.; Tobias, G.; Huh, Y.; Green, M.L.H. Purification and Opening of Carbon Nanotubes Using Steam. Carbon 2006, 44, 2855-2858. [CrossRef]

30. Karmakar, A.; Bratton, S.M.; Dervishi, E.; Ghosh, A.; Mahmood, M.; Xu, Y.; Saeed, L.M.; Mustafa, T.; Casciano, D.; Radominska-Pandya, A.; et al. Ethylenediamine functionalized-single-walled nanotube (f-SWNT)-assisted in vitro delivery of the oncogene suppressor p53 gene to breast cancer MCF-7 cells. Int. J. Nanomed. 2011, 6, 1045-1055. [CrossRef]

31. Ferrari, A.C.; Robertson, J. Interpretation of Raman spectra of disordered and amorphous carbon. Phys. Rev. B 2000, 61, 14095-14107. [CrossRef]

32. Laudenbach, J.; Gebhardt, B.; Syrgiannis, Z.; Hauke, F.; Hirsch, A.; Maultzsch, J. Raman bands of nanographene flakes on carbon nanotubes after oxidation. Phys. Status Solidi B 2013, 250, 2687-2691. [CrossRef]

(C) 2018 by the authors. Licensee MDPI, Basel, Switzerland. This article is an open access article distributed under the terms and conditions of the Creative Commons Attribution (CC BY) license (http:/ / creativecommons.org/licenses/by/4.0/). 